\title{
BMJ Open Health-related behaviours and perceptions among physicians: results from a cross-sectional study in Israel
}

\author{
Rachel Wilf Miron, ${ }^{\oplus 1}$ Lilach Malatskey, ${ }^{2}$ Laura J Rosen ${ }^{\oplus 1}$
}

To cite: Wilf Miron R, Malatskey L, Rosen LJ. Health-related behaviours and perceptions among physicians: results from a cross-sectional study in Israel. BMJ Open 2019;9:e031353. doi:10.1136/ bmjopen-2019-031353

- Prepublication history and additional material for this paper are available online. To view, please visit the journal online (http://dx.doi.org/10.1136/ bmjopen-2019-031353)

Received 29 April 2019 Revised 21 August 2019 Accepted 29 August 2019

Check for updates

(C) Author(s) (or their employer(s)) 2019. Re-use permitted under CC BY-NC. No commercial re-use. See rights and permissions. Published by BMJ.

${ }^{1}$ Department of Health Promotion, School of Public Health, Sackler Faculty of Medicine, Tel Aviv University, Tel Aviv, Israel

${ }^{2}$ Public Health Department, Health Sciences Faculty, BenGurion University of the Negev, Be'er-Sheva, Israel

Correspondence to Dr Rachel Wilf Miron; r.w.miron@gmail.com

\section{ABSTRACT}

Objectives Physicians' demanding work conditions may reduce the time and energy required for maintaining healthy lifestyles. This study examined health-related behaviours, perceived health status and emotional stress among physicians, and analysed the effects of personal and work characteristics on these endpoints.

Design A cross-sectional study using a digital questionnaire.

Setting and participants All 25590 physicians who were members of the Israeli Medical Association in 2015 were invited to participate by email. of 14694 who opened the e-mail, 4832 (32.9\%) responded.

Outcome measures Survey topics included physical activity (PA), nutrition and eating habits, smoking, sleep, perceived health status and emotional stress, body mass index (BMI) and contact with a regular physician, as well as personal and work characteristics. Univariate and multivariate analyses were performed.

Results Of the 4832 respondents, $21 \%$ reported poor or fair health status, $36 \%$ felt considerable emotional stress, $57 \%$ were overweight or obese (according to $\mathrm{BMl} \geq 25 \mathrm{~kg} /$ $\mathrm{m}^{2}$ ), $71 \%$ did not meet the recommended PA level, $79 \%$ did not meet a composite measure of healthy nutrition, $8 \%$ were current smokers, $25 \%$ slept 5 hours or less and $57 \%$ did not have a regular physician. Residents and hospital physicians reported significantly less healthy lifestyles, lower perceived health status and higher stress levels, compared with senior and community physicians. Multivariate analysis demonstrated that being female ( $\mathrm{OR}=0.74,95 \% \mathrm{Cl}=0.64$ to 0.85$)$, younger $(0.69,0.64$ to 0.74$)$, having poor nutrition $(0.66,0.55$ to 0.78$)$, not meeting PA targets $(0.68,0.57$ to 0.82$)$, inadequate sleep $(0.54,0.40$ to 0.56$)$ and perceived poor health status $(0.48$, 0.40 to 0.56 ) were significantly associated with high stress levels $(p<0.001)$.

Conclusions The unfavourable health behaviours reported among Israeli physicians may have negative effects on their health and well-being. An intervention program to help physicians to adopt a healthier lifestyle is urgently needed.

\section{INTRODUCTION}

Non-communicable diseases, comprising mainly cardiovascular diseases, diabetes, cancer and chronic respiratory diseases, are the leading causes of death globally, accounting for $68 \%$ of deaths in $2012 .{ }^{1}$

\section{Strengths and limitations of this study}

This national study portrayed the health behaviours of a relatively large number of respondents $(n=4832)$, the largest of its kind in Israel.

- The study questionnaire covered a large number of health behaviours and perceptions, allowing to portray a relatively comprehensive picture of Israeli physicians' wellness.

- The physicians were not asked if they undergo regular screening tests as recommended.

- A response rate of $33 \%$ is a barrier to generalising the findings to a larger physician population.

- Physicians who felt more positive about their health behaviours were more likely to respond to the survey; therefore, the actual health status of the physicians is likely to be worse than that described.

The prevalence of lifestyle-related diseases, such as obesity and type 2 diabetes, has risen considerably in the last decades. Two meta-analyses of large cohort studies have demonstrated that a combination of at least four lifestyle factors of the following: obesity, alcohol consumption, smoking, unhealthy nutrition and not meeting the guidelines for physical activity (PA), was associated with $66 \%$ of mortality risk. ${ }^{2} 3$ Therefore, promotion of healthy behaviours has become a public health imperative and preventive medicine concern.

As a professional group, physicians have a unique opportunity to promote healthy lifestyle. Most adults in western countries meet their physician at least once a year. Moreover, patients view physicians as a reliable and influential source of knowledge and advice regarding health-related behaviours. ${ }^{4}$ Physicians with healthy habits are more likely to discuss those habits with their patients, to lead an effective dialogue and to motivate their patients to adopt a healthy lifestyle. ${ }^{56}$ Frank et al demonstrated that physicians' advice was perceived as more reliable if the physician disclosed his or her own health behaviours with the patient. ${ }^{7}$ 
However, physician health is not self-understood, given the unique work conditions of physicians, including long work shifts and calls, and long weekly work hours compared with the general population. In their leisure time, they often need to dedicate time to remaining up-to-date in their profession. As a result, physicians have greater struggles with work-life balance than do other workers. ${ }^{8}$ They might, therefore, lack the time and energy required for maintaining healthy lifestyles. Physicians work in emotionally charged situations, associated with suffering, fears and death, and are exposed to considerable stress. Concerns about physicians' mental health were documented as early as 1883 when Mattison described opium addicts among physicians. ${ }^{9}$ In 1973, the American Medical Association published a report that related to psychiatric disorders that might impair physician functioning. ${ }^{10}$ Burnout was mentioned as an entity for the first time in 1975 to describe 'failure or exhaustion because of excessive demands on energy, strength or resources' among the staff of alternative self-help clinics in the USA. ${ }^{11}$ Burnout among physicians may lead to loss of enthusiasm for work, feelings of cynicism and a low sense of personal accomplishment, despite being highly motivated at the start of their careers. ${ }^{8} 1213$

Physician health and well-being have recently become the focus of international concern as physicians are important 'citizens' of the healthcare system. Therefore, their wellness is crucial to its function. Physician ill-health negatively affects productivity, efficiency, quality of patient care and physician retention. ${ }^{14}$

The Canadian, British and American Medical Associations, as well as healthcare organisations, have recently begun to recognise the potential health risks involved with the medical profession. They have created programmes to address the health needs of their members, such as the British Medical Association counselling service, the Doctor Advisor Service, an online physician health and wellness resource prepared by Canadian physician health and e-learning experts, as well as biennial international conferences on physician health. ${ }^{15-17}$

Israel is characterised by a low hospital bed-to-population ratio and a high occupancy rate compared with other Organization for Economic Co-operation and Development countries and the European Union (EU) average. The physician-to-population ratio is somewhat lower than that of the EU countries, with downward trending. ${ }^{18}$ The Israeli healthcare system is characterised by a unique reimbursement mechanism, which dictates a 'multiemployer' reality, especially for senior hospital physicians, who frequently work full-time as salaried employees in the public system and continue their working day in the evenings as self-employed physicians for a health fund (health maintenance organisation) or in their private clinic. ${ }^{19}$ The above-mentioned combination of deficient infrastructures and unique reimbursement methods creates considerable workloads and possibly also a greater work-life imbalance.
Little is known about health and well-being in the Israeli physician population. The Israeli Medical Association (IMA) is an independent professional body that represents $95 \%$ of Israeli physicians. As a part of its mission, the IMA has recently initiated efforts to promote health-related behaviours among physicians, including the current study.

The objectives of this study were to examine health-related behaviours and perceptions among physicians, and to analyse the effect of personal and work characteristics on these endpoints.

\section{METHODS}

\section{Study design and participants}

For this cross-sectional study, all IMA members were contacted by email and asked to complete an electronic questionnaire (online supplementary file 1). The IMA e-mail list comprised $95 \%$ of the country's physicians. E-mails were sent in July 2015 with a short cover letter by the IMA president, containing a link to the survey. Three reminders were sent, between July and August 2015, to members who did not open the mail message.

\section{Questionnaire}

The digital format dictated the design of a short questionnaire (requiring $120 \mathrm{~s}$ to complete), suitable for computers or smartphones. The questionnaire was developed in collaboration with IMA senior representatives and a panel of experts from the fields of medicine, medical ethics, health promotion, sports medicine, nutrition and biostatistics. Survey topics included PA (two questions), nutrition and eating habits (seven questions), smoking (two questions), sleep (one question), perceived health status (one question), perceived emotional stress (one question), contact with a regular personal physician (one question), height and weight for the calculation of body mass index (BMI), as well as personal and work characteristics (eight questions). Questions were based on validated Hebrew and international questionnaires, adapted to the digital format. ${ }^{20-22}$ The survey tool was subjected to internal validation by the expert panel and a convenience sample of 30 respondents were asked to provide feedback on clarity, relevance and other aspects of the tool.

Age, sex and specialty were obtained from IMA members who did not open the mail, to enable comparison of respondents with non-respondents.

\section{Definition of variables}

Meeting PA guidelines: Performing at least 150 min of leisure-time PA in an average week.

A composite 'healthy nutrition' measure was defined, which included: eating breakfast, eating lunch, following the principles of a Mediterranean diet ${ }^{23}$ (consuming fruits and vegetables, whole wheat, legumes, nuts, fish, poultry and low-fat dairy products), consuming five units of fruits and vegetables, drinking eight cups of waterevery day or almost every day, consuming processed food 
or sugary drinks-never or less than once a week. Healthy nutrition was defined as complying with six or seven of the seven parameters.

Perceived health status: Physicians were asked, 'In general, how would you define your health status?' (excellent, very good, good, fair or poor).

Perceived emotional stress: 'To what extent do you experience emotional stress?' (very low, low, moderate, high and very high).

\section{Statistical analysis}

Continuous variables were summarised as mean and SD. Categorical variables were summarised as number and percentage. $\chi^{2}$ and $\mathrm{t}$ tests were employed for univariate analysis and comparisons among subgroups. Logistic regression models were estimated for perceived health and stress status as dependent variables. A binomial variable was defined for the multivariate analysis: for perceived health status: $0=$ poor or fair and $1=$ good, very good or excellent; for emotional stress: $0=$ very low, low or moderate and $1=$ high or very high.

\section{Patient and public involvement}

It was not appropriate or possible to involve patients or the public in this work as it was not relevant to the research question.

\section{RESULTS}

Of 25590 e-mail addresses that were contacted, 14694 physicians $(57.4 \%)$ opened the email, 5374 clicked on the link to the questionnaire and $4832(32.9 \%)$ completed and submitted the questionnaire. Since only half of IMA e-mails to the physicians represented by this organisation are ever opened by the physicians, we calculated effective response rate as the proportion of physicians who opened the e-mail and submitted the questionnaire. The respondents represent approximately one-fifth of all physicians practising in Israel. Sixty per cent of the respondents were males, $36 \%$ were aged 44 years or younger and $15 \%$ were over 65 years.

Three parameters were available for comparison of respondents with non-respondents: age, sex and specialty. Age and sex distributions were similar among respondents and non-respondents. The main specialties of the respondents were internal medicine (19\%), surgery and surgical subspecialties $(18 \%)$, general practice $(13 \%)$ and paediatrics (12\%). Among non-respondents, specialty distribution differed slightly, however with statistical significance $(\mathrm{p}<0.0001)$ (table 1$)$.

Nineteen per cent of the respondents were residents or fellows, $71 \%$ were seniors and $8 \%$ were general physicians (which is not a specialty in Israel). (table 2). Physicians were asked to state their main work settinghospital, community or similar work volume in both hospital and community. Fifty-one per cent worked in hospitals, $31 \%$ in the community and $6 \%$ in both settings. The remainder worked in Ministry of Health facilities and other settings. These data are comparable with national figures that indicate that the main work settings of physicians are the hospital $(54 \%)$ and the community $(39 \%){ }^{24}$

Respondents, whose major work setting was the hospital, were younger, more likely male and more likely in residency, compared with those working in the community;

Table 1 Characteristics of respondents and non-respondents (\%)

\begin{tabular}{|c|c|c|c|}
\hline Variable & $\begin{array}{l}\text { Non-respondents } \\
(\mathrm{n}=20085)\end{array}$ & $\begin{array}{l}\text { Respondents } \\
(\mathrm{n}=4832)\end{array}$ & $P$ value \\
\hline \multicolumn{4}{|l|}{ Age (years) } \\
\hline$<35$ & 14.5 & 12.5 & \\
\hline $35-44$ & 23.7 & 23.7 & \\
\hline $45-54$ & 21.4 & 21.4 & 0.104 \\
\hline $55-64$ & 21.3 & 26.7 & \\
\hline $65+$ & 17.5 & 14.7 & \\
\hline Unknown & 1.7 & 1.1 & \\
\hline \multicolumn{4}{|l|}{ Gender } \\
\hline Female & 38.8 & 40.3 & 0.161 \\
\hline Male & 60.4 & 59.7 & \\
\hline \multicolumn{4}{|l|}{ Medical specialty } \\
\hline Paediatrics & 12.2 & 12.8 & \\
\hline General practice & 13.1 & 13.6 & \\
\hline Internal medicine & 20.3 & 19.3 & \\
\hline Surgical specialties & 14.7 & 17.9 & $<0.0001$ \\
\hline Anesthesiology & 4.4 & 0.4 & \\
\hline Obstetrics and gynaecology & 7.1 & 8.0 & \\
\hline
\end{tabular}


Table 2 Demographic characteristics of respondents by work setting (\%)

\begin{tabular}{|c|c|c|c|c|c|}
\hline Main work setting & $\begin{array}{l}\text { Hospital } \\
(n=2472)\end{array}$ & $\begin{array}{l}\text { Community } \\
(n=1482)\end{array}$ & $\begin{array}{l}\text { Combined* } \\
(n=282)\end{array}$ & $\begin{array}{l}\text { Total } \\
(n=4832) \dagger\end{array}$ & $P$ value \\
\hline \multicolumn{6}{|l|}{ Age (years) $\ddagger$} \\
\hline $35-44$ & 30.4 & 18.7 & 26.0 & 23.7 & \multirow{2}{*}{$<0.0001$} \\
\hline $45-54$ & 19.3 & 26.3 & 31.7 & 21.4 & \\
\hline \multicolumn{6}{|l|}{ Gender } \\
\hline Female & 36.5 & 49.1 & 36.5 & 40.3 & \multirow[t]{2}{*}{$<0.0001$} \\
\hline Male & 63.5 & 50.9 & 63.5 & 59.7 & \\
\hline \multicolumn{6}{|l|}{ Level of training§ } \\
\hline
\end{tabular}

*Similar work volume in both hospital and community.

†The 'total' column contains data on 596 (12\%) respondents who did not define their main work setting by one of the three major categories (ie, worked for the Ministry of Health, worked only in a private clinic or in an 'unspecified' work setting).

‡Age data were missing for $52(1.1 \%)$ respondents.

$\S$ Data on level of training were missing for $65(1.3 \%)$ respondents.

yet senior physicians were the majority $(63 \%)$ of hospital respondents (table 2 ).

Twenty-one per cent reported poor or fair health status, with no significant difference by workplace. Thirty-six per cent reported a high or very high level of emotional stress. More females reported high stress than males $(40.5 \%$ and $33.2 \%$, respectively, $\mathrm{p}<0.0001)$. Residents were the subgroup with the highest stress levels: $49.8 \%$ reported high or very high stress, compared with $33.5 \%$ of seniors $(p<0.0001)$. The hospital setting was associated with a higher perceived level of considerable stress than the community setting: $43.4 \%$ and $30.6 \%$, respectively $(\mathrm{p}<0.0001)$ (table 3$)$. BMI was in the normal range for $41.7 \%$ of respondents, with $41.4 \%$ and $15.9 \%$ overweight and obese, respectively. Overweight and obesity $\left(\mathrm{BMI} \geq 25 \mathrm{~kg} / \mathrm{m}^{2}\right)$ were more prevalent among male than female respondents: $67.2 \%$ and $42.2 \%$, respectively $(\mathrm{p}<0.0001)$, and among those working in the community than the hospital (table 3).

Twenty-eight per cent reported not exercising at all, while $29 \%$ met the recommended PA target $(\geq 150 \mathrm{~min}$ weekly). A higher proportion of male than female respondents met the PA target $332.5 \%$ and $27.2 \%$, respectively, $\mathrm{p}<0.0001$ ). Only $15.0 \%$ of residents, compared with $34.1 \%$ of seniors, met the target. Community physicians were significantly more active (table 4 ). Twenty-one per cent complied with the 'healthy nutrition measure' (six or seven of seven healthy nutrition parameters). Compliance with separate nutritional items is detailed in table 4 . Overall, females had healthier nutritional habits than males. Most eating habits were healthier among community than hospital physicians (table 4). Among residents, hospital, community and overall respondents, $16 \%, 10 \%$, $7 \%$ and $8.5 \%$ were current smokers, respectively. Twenty-five per cent reported sleeping 5 hours or less on an average night, while only $23 \%$ slept 7 or more hours, as recommended. Only $16 \%$ of hospital physicians slept 7 or more hours nightly. Forty-three per cent of respondents (38\% and $46 \%$ in the hospital and community, respectively) had a personal physician on a regular basis.

The multivariate analysis revealed that the variables younger age, senior status, good nutrition score, meeting the PA target and lower emotional stress were all associated with the perception of good health status. The variables female sex, younger age, poor nutritional habits, not achieving the recommended PA target and inadequate sleep were all associated with high stress levels (table 5).

\section{DISCUSSION}

The results from a national health survey show that health-related behaviours of Israeli physicians are far from optimal. Compared with the Israeli population of similar socioeconomic background, ${ }^{22} 2526$ fewer respondents achieve the recommended PA target, more are overweight, but fewer smoke. Compared with the Canadian and US physicians, populations for which these issues have been studied in the last decade, fewer Israeli physicians met PA guidelines, more were overweight or obese and more were current smokers. ${ }^{21} 2728$ Compared with their Canadian colleagues, Israeli physicians tended more frequently to perceive their health as fair or poor, by 2.3 times. $^{21}$ 
Table 3 Health status by work setting (\%)

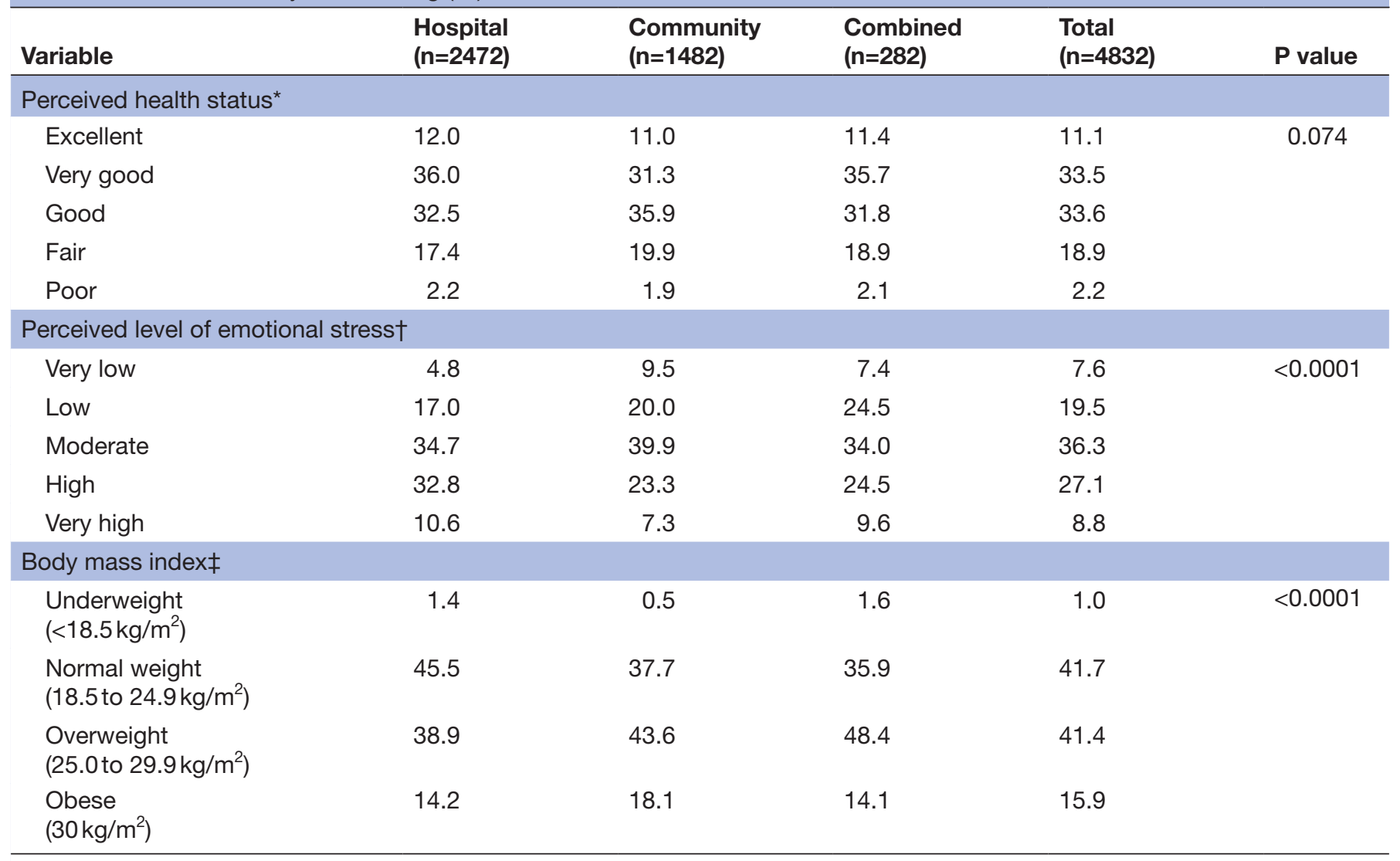

${ }^{*} \mathrm{~N}=4796 ; 36(0.7 \%)$ respondents did not report perceived health status.

$\dagger \mathrm{N}=4798 ; 34(0.7 \%)$ respondents did not report perceived emotional stress.

$\ddagger \mathrm{N}=4349$; $483(9.0 \%)$ respondents did not report weight and/or height data.

Large and comprehensive studies on health-promoting behaviours to prevent chronic illness among physicians are few, and use different designs. Canadian and some US studies demonstrated better practices among physicians than comparable general populations. ${ }^{28}{ }^{29}$ However, these findings are not universal: junior British doctors met PA targets less often than the general population ${ }^{30}$; Bahrain primary care physicians were less likely to meet PA targets or to have BMI at the normal range than the general population. ${ }^{31}$ In California, more physicians were not exercising at all or exercising only occasionally, and fewer tended to eat breakfast regularly, compared with the adult US population. ${ }^{32}$ Seventy-one per cent of Australian junior doctors were concerned about their own health. ${ }^{33}$

Worldwide, physicians are known as 'bad' patients who do not have a regular physician for their personal health. Our finding that two-thirds of hospital-based physicians do not have a regular personal physician supports a previous study that demonstrated that $82 \%$ of hospital physicians had been asked by their colleagues to provide 'hallway medicine', and $91 \%$ of them agreed. ${ }^{34}$

High levels of emotional stress have been repeatedly described among physicians. For example, $49 \%$ of Canadian female physicians reported usually having high levels of stress ${ }^{35}$; and $70 \%$ of Australian junior physicians reported experiencing high levels of stress at work. ${ }^{33}$ When left untreated, chronic stress may lead to burnout. ${ }^{12}$ West and his colleagues listed diverse work-related drivers, such as excessive workload, work inefficiency (ie, clerical burdens) and loss of control and autonomy, as contributors to physician burnout. ${ }^{36}$ Hospital-based Chinese physicians with a shift-based schedule and a heavy workload were more susceptible to burnout. Imbalance between high job demand and low self-control indicated a high level of occupational stress exposure. ${ }^{37}$

The current study demonstrated higher perceived emotional stress among hospital physicians compared with community-based physicians. In Israel, $61 \%$ of the physicians are salaried, $33 \%$ are both salaried and self-employed while $6 \%$ are exclusively self-employed. ${ }^{24}$ Less sense of control over work demands among salaried physicians in the hospital setting, compared with self-employed physicians in the community setting, might be related to higher stress. Why do physicians, who enjoy high health literacy, make suboptimal use of their knowledge and skills to adopt healthy lifestyles? As mentioned above, the reimbursement mechanisms of the Israeli healthcare system contribute to long work hours. ${ }^{19}$ Physicians may, therefore, lack the time and energy to invest in healthy lifestyles. Unsurprisingly, excessive work hours 
Table 4 Health-related behaviour by work setting (\%)

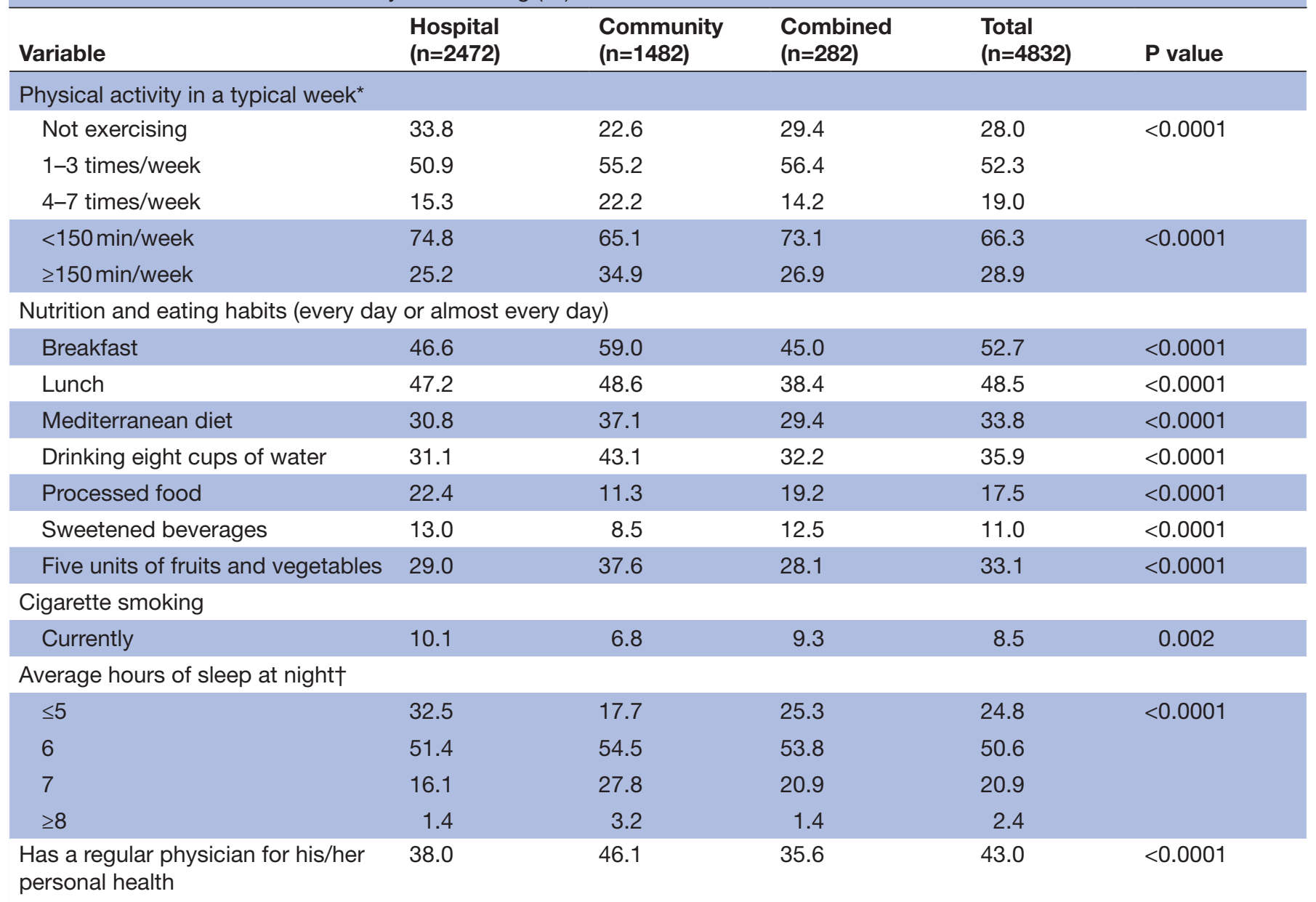

${ }^{*} \mathrm{~N}=4600 ; 232$ (4.8\%) respondents did not provide complete information on physical activity.

$\dagger \mathrm{N}=4769 ; 63$ (1.3\%) respondents did not report sleeping hours.

were associated with lack of exercise, not eating breakfast, less sleeping hours and higher BMI. ${ }^{28} 32$

We recently administered the same questionnaire used in the current study to 151 second-year medical students (a response rate of $88 \%$ from 170 students, mean age 24.7 years, SD 2.7 years). The students demonstrated considerably better health behaviours than did residents (Wilf Miron R, Comparison between health-related behaviours of medical students and residents). Understanding the nature of the 'slippery slope' is of great importance in regard to health-related behaviours along the clinical years of medical school and during residency.

Associations shown between achieving PA target and reducing burnout ${ }^{38}$ should encourage health organisations as well as individuals to promote and improve lifestyle areas, such as PA, nutrition and sleep, for the benefit of health and health perception, and to reduce stress and burnout. Furthermore, improved personal health behaviours of physicians might affect their patients, and thus society at large. ${ }^{56}$

Following the findings of this study, the IMA has accelerated a number of diverse programmes to promote health-related behaviours to prevent chronic illness among its members, such as designating smoking cessation workshops for physicians, guided exercise sessions and personal trainer service for physicians and their spouses, stress and resilience workshops, and a position paper urging the serving of healthy food at staff meetings and conventions. The main findings of the current survey, as well as a list of resources to promote healthy behaviours, have been distributed to all members of the IMA. ${ }^{39}$ Physicians were encouraged to ask their organisational managements to improve nutritional options at cafeterias and coffee shops at medical facilities.

This study has a number of limitations. A digital survey dictated a relatively short questionnaire. Therefore, important topics, such as physician burnout and complying with immunisation and health screening, were not included. Although the $33 \%$ response rate achieved was declared as the highest response rate ever achieved by the IMA in mail surveys among its members, it can be viewed as a barrier to generalising the findings to a larger physician population. In general, physicians are known as a professional group with low survey response rates, for example, survey response among Canadian physicians was $34.1 \%$ and $29.9 \%$, if contacted by regular mail or 
Table 5 Results of the logistic regression models for health and stress perceptions as dependent variables

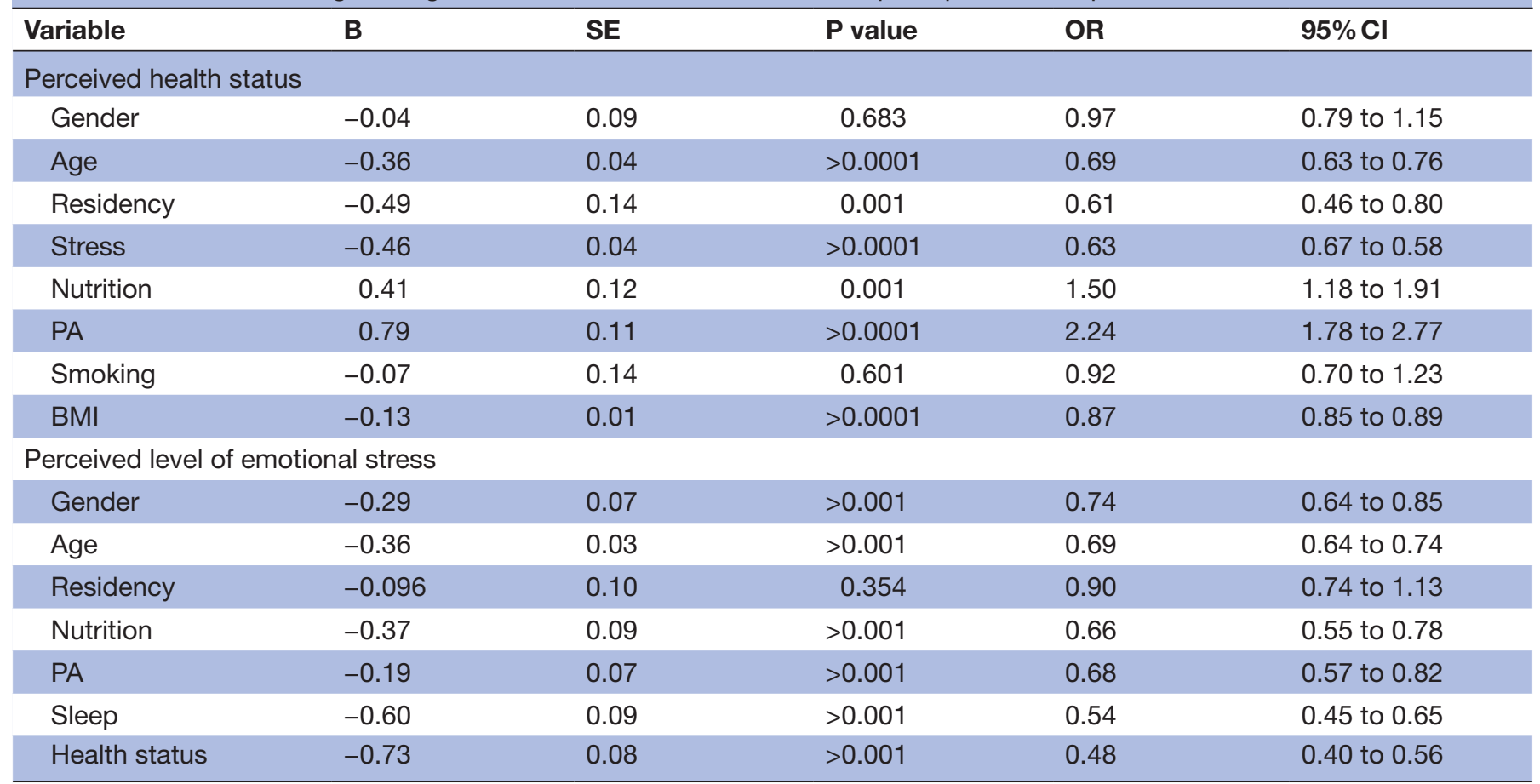

Gender: male=1 and female=0; Residency: resident=1 and attending=0; Nutrition: six to seven items of good nutrition, daily or almost daily=1 and others=0; PA: meets PA guidelines=1 and others=0; Health status: excellent, very good and good=1 and fair or poor=0; Emotional stress: very low, low or moderate $=0$ and high or very high $=1$.

B stands for unstandardised regression coefficient, also termed "unstandardised bata".

BMI, body mass index; PA, physical activity.

e-mail, respectively. ${ }^{40} \mathrm{~A}$ meta-analysis that compared the response rates of e-mail versus mail surveys found that e-mail surveys generally have a lower response rate (about $20 \%$ lower on the average) than mail surveys. ${ }^{41}$

The respondents of the current survey had similar distributions of sex and age in comparison to non-respondents, but the distribution of specialties was different between these groups. We expect that physicians who felt more positive about their health behaviours would be more likely to respond to the survey. If this was, in fact, the case, then the actual health status of the physicians would be worse than that described.

It should be noted that the current study did not measure some important work-related factors, such as shift work or perceived control over work demands that might be relevant for a policy response.

\section{CONCLUSIONS}

Our findings raise concerns about health behaviours of Israeli physicians and point to the urgent need for preventive and health promotion initiatives. Interventions focusing on two stages of the physician's life may be meaningful: medical training, in which students should be provided with healthy lifestyle knowledge and practical tools to help them implement it, and professional work, with a focus on hospitals. Physicians should be provided with healthier food and beverage options at medical facilities, especially during long work hours, and encouraged to partake in PA and stress reduction options. Such interventions could benefit physicians, patients, the community and the healthcare system at large.

Acknowledgements This paper is dedicated to Dr Ronit Peled who passed away while the paper was under preparation. Dr Peled participated in the design of the study and its statistical analysis, has made substantial contributions to the interpretation of the data and was involved in draft revisions. We appreciate the contribution of Leonid Eidelman, MD, the former chairman of the Israel Medical Association, and Tamar Karni, MD, the Chairwoman of the Ethics Bureau at the Israel Medical Association. As part of the Israel Medical Association efforts to promote health-related behaviours among Israeli physicians, they both were responsible for the initial conception of the study and contributed to the development of the research questionnaire.

Contributors RWM led all the stages of the research, from conception to design, interpretation of the data and drafting of all article components. LM made a substantial contribution to the design and the interpretation of the data, and critically revised the article manuscripts. LJR made a substantial contribution to the design of the study and the interpretation of the data, and helped to draft the manuscript.

Funding The authors have not declared a specific grant for this research from any funding agency in the public, commercial or not-for-profit sectors.

Competing interests None declared.

Patient consent for publication Not required.

Ethics approval The survey protocol was reviewed and approved by the Tel Aviv University Institutional Review Board (approval no. 13381298).

Provenance and peer review Not commissioned; externally peer reviewed.

Data availability statement All data relevant to the study are included in the article or uploaded as supplementary information. 
Open access This is an open access article distributed in accordance with the Creative Commons Attribution Non Commercial (CC BY-NC 4.0) license, which permits others to distribute, remix, adapt, build upon this work non-commercially, and license their derivative works on different terms, provided the original work is properly cited, appropriate credit is given, any changes made indicated, and the use is non-commercial. See: http://creativecommons.org/licenses/by-nc/4.0/.

\section{REFERENCES}

1. Estimates GH. Summary tables: death by cause, age and sex 20002012. 2014. Geneva, Switzerland: World Health Organization, 2014.

2. Loef $\mathrm{M}$, Walach $\mathrm{H}$. The combined effects of healthy lifestyle behaviors on all cause mortality: a systematic review and metaanalysis. Prev Med 2012;55:163-70.

3. van Dam RM, Li T, Spiegelman D, et al. Combined impact of lifestyle factors on mortality: prospective cohort study in US women. BMJ 2008;337.

4. Frank E. Physician health and patient care. JAMA: The Journal of the American Medical Association 2004;291:637.

5. Frank E, Segura C, Shen $\mathrm{H}$, et al. Predictors of Canadian physicians' prevention counseling practices. Can J Public Health 2010;101:390-5.

6. Howe M, Leidel A, Krishnan SM, et al. Patient-Related Diet and Exercise Counseling: Do Providers' Own Lifestyle Habits Matter? Prev Cardiol 2010;13:180-5.

7. Frank E, Breyan J, Elon L. Physician disclosure of healthy personal behaviors improves credibility and ability to motivate. Arch Fam Med 2000;9:287-90.

8. Shanafelt TD, Boone S, Tan L, et al. Burnout and satisfaction with work-life balance among US physicians relative to the general US population. Arch Intern Med 2012;172:1377-85.

9. Mattison J. Opium addiction among medical men. Medical Record 1883;23:621-3.

10. The sick physician: impairment by psychiatric disorders, including alcoholism and drug dependence. JAMA 1973;223:684-7.

11. Freudenberger HJ. The staff burn-out syndrome in alternative institutions. Psychotherapy: Theory, Research \& Practice 1975;12:73-82.

12. Kushnir T, Levhar $\mathrm{C}$, Cohen $\mathrm{AH}$. Are burnout levels increasing? the experience of Israeli primary care physicians. Isr Med Assoc J 2004;6:451-5.

13. Soler JK, Yaman H, Esteva M, et al. Burnout in European family doctors: the EGPRN study. Fam Pract 2008;25:245-65.

14. Wallace JE, Lemaire JB, Ghali WA. Physician wellness: a missing quality indicator. The Lancet 2009;374:1714-21.

15. BMA Counselling and the Doctors Advisor Service. Available: http:// www.bma.org.uk/support-at-work/doctors-well-being/aboutdoctors-for-doctors [Accessed 27 May, 2018].

16. ePhysicianHealth. Com - an online physician health and wellness resource. Available: http://ephysicianhealth.com/ [Accessed 27 May 2018].

17. Peters $M$, Hasan $O$, Puddester D, et al. Doctors' health: taking the lifecycle approach. BMJ 2013;347:f7086.

18. Rosen B, Waitzberg R, Merkur S. Israel: health system review. Health Syst Transit 2015;17:1-212.

19. Nissanholtz R, Rosen B. The medical workforce and GovernmentSupported medical education in Israel. Report No. 6 in: healthcare in Israel for overseas readers: a series of six Monographs. Jersualem: Myers-JDC-Brookdale Institute and Jewish Healthcare Foundation Pittsburgh, 2011.
20. The Ministry of health. Health knowledge, attitudes and practice in Israel 2011. publication number 345. Jerusalem: The Ministry of health, 2013.

21. Frank E, Segura C. Health practices of Canadian physicians. Can Fam Physician 2009;55:810-1.

22. Shohat T. A survey of physical activity habits among Israeli adults, 21 and older. : The Israel Center for Disease Control and Sports Directorate 2012.

23. Willett WC, Sacks F, Trichopoulou A, et al. Mediterranean diet pyramid: a cultural model for healthy eating. Am J Clin Nutr 1995;61:1402S-6.

24. Shemesh A, Rotem N, Haklai Z, et al. Employment characteristics of physicians in Israel. Jerusalem: The Ministry of Health and the Central Bureau of Statistics, 2012.

25. Survey S. Report number 1477. 2012. Jersulaem: The Central Bureau of Statistics, 2010.

26. The Ministry of health. Report of the health Minister on smoking in Israel 2015. Jerusalem: The Ministry of health, 2016.

27. Hung OY, Keenan NL, Fang J. Physicians' health habits are associated with lifestyle counseling for hypertensive patients. Am J Hypertens 2013;26:201-8.

28. Stanford FC, Durkin MW, Blair SN, et al. Determining levels of physical activity in attending physicians, resident and fellow physicians and medical students in the USA. Br J Sports Med 2012;46:360-4

29. Dayoub E, Jena AB. Chronic disease prevalence and healthy lifestyle behaviors among US health care professionals. Mayo Clinic Proceedings 2015;90:1659-62.

30. Gupta K, Fan L. Doctors: fighting fit or couch potatoes? Br J Sports Med 2009;43:153-4.

31. Borgan SM, Jassim GA, Marhoon ZA, et al. The lifestyle habits and wellbeing of physicians in Bahrain: a cross-sectional study. BMC Public Health 2015;15:655.

32. Bazargan M, Makar M, Bazargan-Hejazi S, et al. Preventive, lifestyle, and personal health behaviors among physicians. Academic Psychiatry 2009;33:289-95.

33. Markwell AL, Wainer $Z$. The health and wellbeing of junior doctors: insights from a national survey. Med J Aust 2009;191:441-4.

34. Peleg A, Peleg R, Porath A, et al. Hallway medicine: prevalence, characteristics and attitudes of hospital physicians. Isr Med Assoc J 1999;1:241-4.

35. Stewart DE, Ahmad F, Cheung AM, et al. Women physicians and stress. J Womens Health Gend Based Med 2000;9:185-90.

36. West CP, Dyrbye LN, Shanafelt TD. Physician burnout: contributors, consequences and solutions. J Intern Med 2018;283:516-29.

37. Wang Z, Xie Z, Dai J, et al. Physician burnout and its associated factors: a Cross-sectional study in Shanghai. $J$ Occup Health 2014;56:73-83.

38. Weight CJ, Sellon JL, Lessard-Anderson CR, et al. Physical activity, quality of life, and burnout among physician trainees: the effect of a team-based, incentivized exercise program. Mayo Clinic Proceedings 2013;88:1435-42.

39. Health of Israeli physician: A lot to be done. A letter of the physician health Committee. Ramat Gan, Israel: Israeli Medical Association, 2016.

40. Grava-Gubins I, Scott S. Effects of various methodologic strategies: survey response rates among Canadian physicians and physiciansin-training. Can Fam Physician 2008;54:1424-30.

41. Shih T-H, Fan X. Comparing response rates in e-mail and paper surveys: a meta-analysis. Educational Research Review 2009;4:26-40. 